
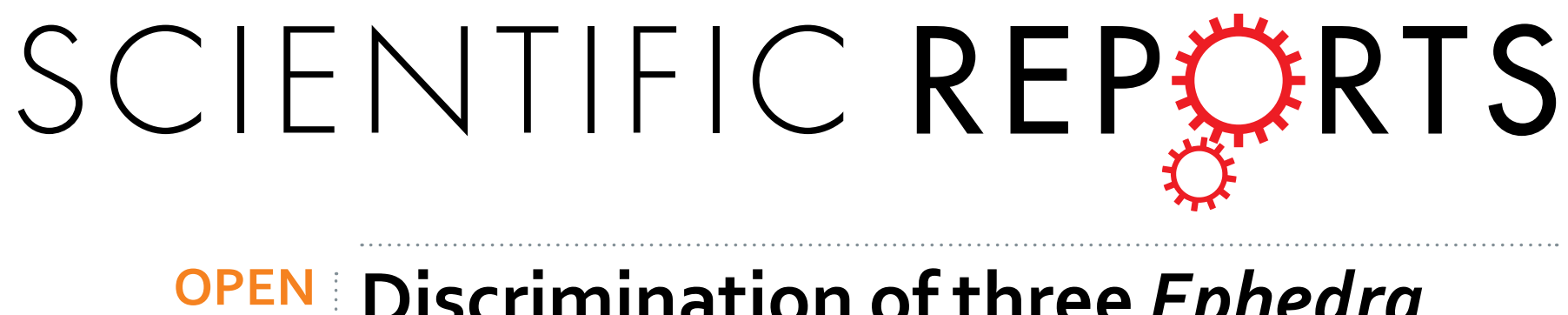

Discrimination of three Ephedra species and their geographical origins based on multi-element

Received: 6 December 2017

Accepted: 22 June 2018

Published online: 06 July 2018

\section{fingerprinting by inductively coupled plasma mass spectrometry}

Xiaofang $\mathrm{Ma}^{1}$, Lingling Fan ${ }^{1}$, Fuying Mao ${ }^{1,2}$, Yunsheng $\mathrm{Zhao}^{1,2,3}$, Yonggang Yan ${ }^{4}$, Hongling Tian ${ }^{5}$, Rui Xu ${ }^{1}$, Yanqun Peng ${ }^{1} \&$ Hong Sui ${ }^{1,2}$

Discrimination of species and geographical origins of traditional Chinese medicine (TCM) is essential to prevent adulteration and inferior problems. We studied Ephedra sinica Stapf, Ephedra intermedia Schrenk et C.A.Mey. and Ephedra przewalskii Bge. to investigate the relationship between inorganic element content and these three species and their geographical origins. 38 elemental fingerprints from six major Ephedra-producing regions, namely, Inner Mongolia, Ningxia, Gansu, Shanxi, Shaanxi, and Sinkiang, were determined to evaluate the importance of inorganic elements to three species and their geographical origins. The contents of 15 elements, namely, N, P, K, S, Ca, Mg, $\mathrm{Fe}, \mathrm{Mn}, \mathrm{Na}, \mathrm{Cl}, \mathrm{Sr}, \mathrm{Cu}, \mathrm{Zn}$, $\mathrm{B}$, and Mo, of Ephedra samples were measured using inductively coupled plasma mass spectroscopy. Elemental contents were used as chemical indicators to classify species and origins of Ephedra samples using a radar plot and multivariate data analysis, including hierarchical cluster analysis (HCA), principal component analysis (PCA), and discriminant analysis (DA). Ephedra samples from different species and geographical origins could be differentiated. This study showed that inorganic elemental fingerprint combined with multivariate statistical analysis is a promising tool for distinguishing three Ephedra species and their geographical origins, and this strategy might be an effective method for authenticity discrimination of TCM.

Ephedrae herba (Mahuang) is a well-known traditional Chinese medicine (TCM) derived from the dried herbaceous stem of Ephedra sinica Stapf (E. sinica), Ephedra intermedia Schrenk et C.A.Mey.(E. intermedia), and Ephedra equisetina Bge ${ }^{1}$. It has been used for more than 5000 years in China ${ }^{2}$. Its main active ingredients are alkaloids, such as ephedrine and pseudoephedrine $e^{3,4}$. Flavonoids ${ }^{5}$, polysaccharides ${ }^{6}$, phenolic compounds ${ }^{7}$, and proanthocyanidins ${ }^{8}$, are also its active constituents. Mahuang relieves asthma and promotes diuresis and sweat. In modern TCM, it has been used to treat rheums, asthma, fever, rheumatoid arthritis ${ }^{9}$, and cough with dyspnea.

Ephedra is widely distributed in China, except in the lower reaches of the Yangtze River and the Pearl River Basin, and is especially common in the arid and semiarid regions of the northwest territories of China, such as Ningxia, Inner Mongolia, Sinkiang, and Gansu provinces ${ }^{10,11}$.

The market demand of Mahuang is strong, and its wild resources have been severely reduced by excessive harvesting ${ }^{12}$. Many Ephedra plants are morphologically similar, making their identification based on morphology very difficult, and some adulterants of Ephedra species are confused with the medicinal plants. The number of poor-quality Mahuang is increasing in the market, and the inferior medicinal materials mainly come from non-genuine production areas and non-medicinal Ephedra species, such as Ephedra przewalskii Stapf (E.

${ }^{1}$ Ningxia Medical University Pharmacy College, Yinchuan, 750004, Ningxia, China. ${ }^{2}$ Ningxia Research Center of Modern Hui Medicine Engineering and Technology, Yinchuan, 750004, Ningxia, China. ${ }^{3}$ Key Laboratory of Hui Ethnic Medicine Modernization, Ministry of Education, Yinchuan, 750004, Ningxia, China. ${ }^{4}$ Shaanxi University of Chinese

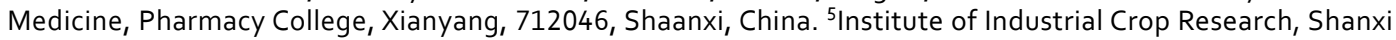
Academy of Agricultural Sciences, Fenyang, 032200, Shanxi, China. Correspondence and requests for materials should be addressed toY.Z. (email: zwhjzs@126.com) 
przewalskii), which is easily confused with the medicinal Ephedra plants. E. intermedia and E. przewalskii both have two-lobed or three-lobed leaves ${ }^{13}$, which increases the difficulty in distinguishing them. The discrimination of species and geographical origins of medicinal Ephedra plants is essential to prevent adulteration and inferior problems ${ }^{14}$. Medicinal materials from different geographical origins are difficult to distinguish for the naked eye. Therefore, the quality control of genuine TCM often relies on chemical analysis.

The current elemental fingerprint study differentiated crops based on element composition and multivariate statistical analysis ${ }^{15}$. However, few fingerprints were reported on the inorganic element discrimination of Ephedra ${ }^{16}$. Inorganic elements contribute to the medicinal quality of $\mathrm{TCM}^{17}$. Some inorganic elements play important roles in the formation of active components, which are responsible the curative properties ${ }^{18,19}$. Therefore, constructing elemental fingerprints is useful in identifying the geographical origin and species of TCM.

The study on inorganic elements is very little in Mahuang, and the 15 inorganic elements of $\mathrm{N}, \mathrm{P}, \mathrm{K}, \mathrm{S}, \mathrm{Ca}, \mathrm{Mg}$, $\mathrm{Fe}, \mathrm{Mn}, \mathrm{Na}, \mathrm{Cl}, \mathrm{Sr}, \mathrm{Cu}, \mathrm{Zn}, \mathrm{B}$, and $\mathrm{Mo}$ are indispensable and irreplaceable for plant growth, therefore, these elements were selected in this study. According to the Chinese Pharmacopoeia ${ }^{1}$, Mahuang, as a traditional Chinese medicine, should be collected in the autumn growth stage. So the effects of the growth phase on these elements were the same for Mahuang, which increased the reliability for research.

In this study, we determined the 15 inorganic elements in E. sinica, E. intermedia, and E. przewalskii using ICP-MS, investigated the elemental compositions, discriminated three Ephedra plants from different regions through multivariate analysis, and further established a reliable method for differentiating the three Ephedra species. Results showed that the combination of inorganic elemental fingerprint with multivariate statistical analysis is a valuable tool to discriminate the geographical origins of Mahuang.

\section{Results and Discussion}

Method validation. 15 elements were measured by external calibration using the ICP-MS elemental standard substances. Slopes of calibration curves were sensitive, and their correlation coeffcients all reached above 0.9995. The relative standard deviation (RSD), which stood for the precision, ranged from $0.02 \%$ to $2.6 \%$. Withinday repeatability was $<3.4 \%$. The limit of detection (LOD) values were determined by using signalto-noise ratios of 3:1, and Tables S1 showed the LODs determined in digestion solutions of plants samples for ICP-MS. The recoveries from plant sample S-NX3 ranged from $94 \%$ to $117 \%$ for ICP-MS.

Element contents of samples. The contents of elements are shown in Supplementary Table S1. N content was the highest among the 15 elements. The sample of S-NM2 contained the lowest N content, and I-GS11 accumulated the highest $\mathrm{N}$ content, ranging extensively from 12523.58 to $34283.81 \mathrm{mg} / \mathrm{kg}$. Mo content was the lowest among the 15 elements. The lowest and highest Mo contents occurred in S-NM2 and I-GS8, respectively, with contents varying from 0.59 to $1.54 \mathrm{mg} / \mathrm{kg}$. Differences in element contents are due to different growth habits. The element contents of plants are affected by several factors, including plant characteristics (e.g., biological status, species), environmental conditions (e.g., humidity, temperature), and soil characteristics (e.g., pH, mineral (composition $)^{20}$.

Construction of inorganic elemental fingerprint. To demonstrate the distribution rules of the elemental contents, we used the 15 elements to construct an inorganic elemental fingerprint based on the results of quantitative detection through ICP-MS. For convenience, the contents of several elements were narrowed or expanded to the same order of magnitude. Cu and Mo were expanded 100-fold; B and $\mathrm{Zn}$ were expanded tenfold; $\mathrm{Ca}, \mathrm{Mg}$, $\mathrm{P}, \mathrm{K}, \mathrm{Fe}$, and $\mathrm{S}$ were reduced tenfold; and $\mathrm{N}$ was reduced 100-fold) ${ }^{21}$. The 15 elements of the 38 Ephedra samples were drawn in one plot for comparison, as shown in Fig. 1.

Clearly, the fingerprints of three Ephedra species exhibited a common character based on the elements average contents (Fig. 1A). All Ephedra samples also showed a similar peak (Fig. 1B-D), the content of an individual element was always maintained within a certain range ${ }^{22}$ for the samples of different geographical origins. However each element content was different in these fingerprints, and the differences in the elemental contents were related to the diverse origins and species of Ephedra. The elemental contents order of 3 Ephedra species were E. intermedia $>$ E. przewalskii $>$ E. sinica except for $\mathrm{P}, \mathrm{S}, \mathrm{Cl}$, and Mo. Especially for $\mathrm{Ca}, \mathrm{N}, \mathrm{K}, \mathrm{Sr}, \mathrm{B}$ and $\mathrm{Cu}$, the elemental contents in E. intermedia were significantly higher than those in $E$. sinica. Therefore, the elemental fingerprints of Ephedra samples distinguished between E. intermedia and E. sinica. Nevertheless, the elemental fingerprints of Ephedra samples difficultly distinguish E. przewalskii from E. intermedia and E. sinica, and can't differentiate the Ephedra samples from different geographical origins, so the hierarchical cluster analysis (HCA) was subsequently performed.

Sample distribution according to HCA. HCA of the samples was performed to distinguish among the three Ephedra species in samples and the different origins of E. sinica and E. intermedia based on all the elemental data. Ephedra samples of different species were separated into three clusters based on the dendrogram cut at distance of 15 (Fig. 2A) ${ }^{23}$. The first cluster comprised sixteen E. sinica and two E. intermedia samples, the second cluster consisted of fourteen E. intermedia and one E. sinica samples, followed by a third cluster of E. przewalskii. The cluster results were in agreement with the actual species of Ephedra samples, especially for E. przewalskii, which was usually considered as a counterfeit herb. Thus, it can be completely separated from medicinal Ephedra (E. sinica and E. intermedia). These results implied that element information can be suitably utilized to classify Ephedra samples of different species. 

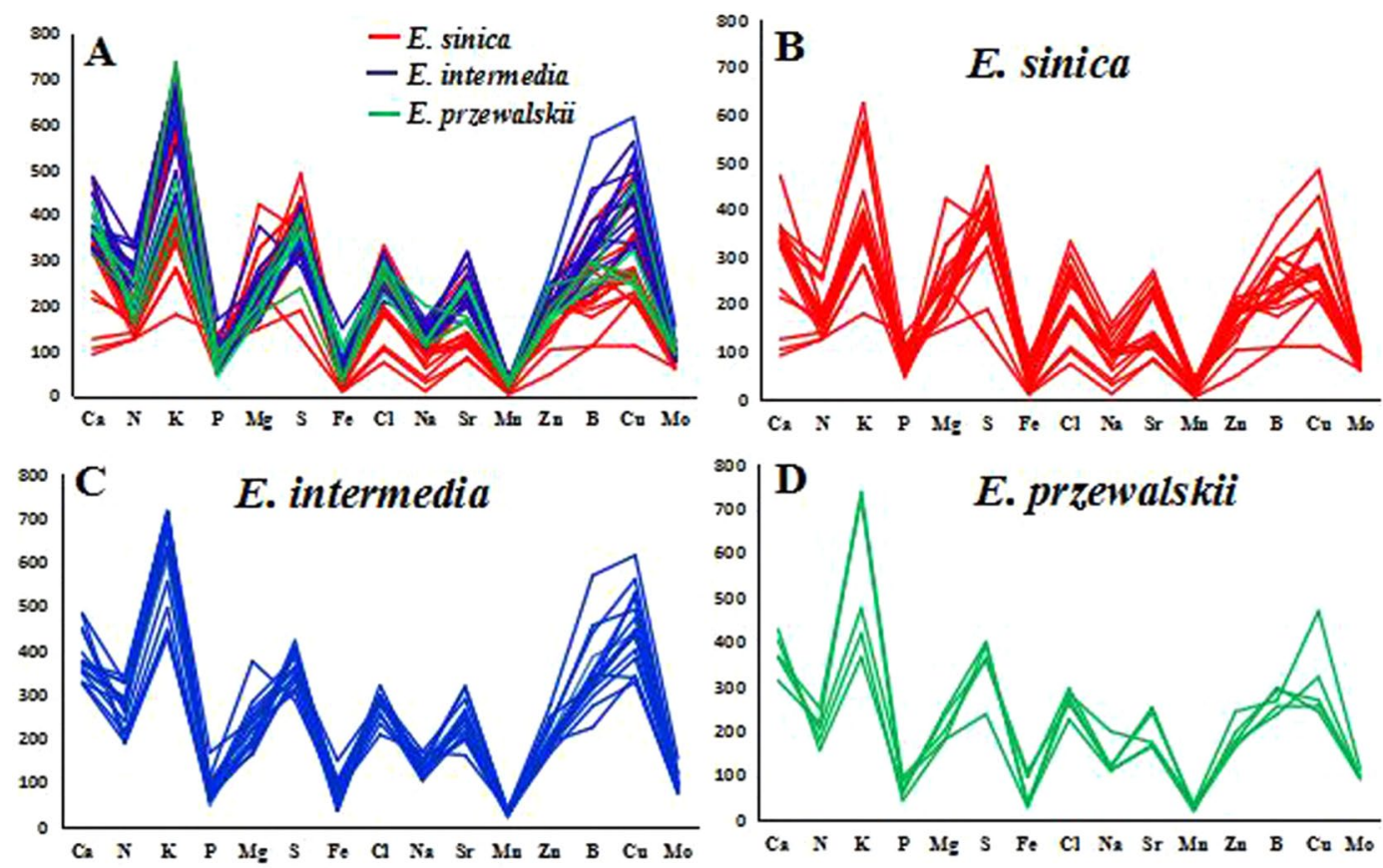

Figure 1. The element fingerprint common character of Ephedra samples. (A) Fingerprint character of elements average contents from three Ephedra species; (B) Elemental fingerprint character of E. sinica from 17 different origins; (C) Elemental fingerprint character of E. intermedia from 16 different origins. (D) Elemental fingerprint character of E. przewalskii from 5 different origins. The contents of several elements were narrowed or expanded to the same order of magnitude: $\mathrm{Cu}$ and Mo were expanded 100-fold; $\mathrm{B}$ and $\mathrm{Zn}$ were expanded ten fold; $\mathrm{Ca}, \mathrm{Mg}, \mathrm{P}, \mathrm{K}, \mathrm{Fe}$, and $\mathrm{S}$ were reduced ten fold; and $\mathrm{N}$ was reduced 100 -fold.

The E. sinica samples from different origins were separated into five clusters based on a dendrogram cut at a distance of 15 (Fig. 2B). The first, second, third, fourth, and fifth clusters were composed of E. sinica samples from Inner Mongolia (4), Sinkiang (1), Gansu Province (3), Shanxi (3), and Shaanxi (2) and Ningxia (4), respectively.

E. intermedia samples from different origins were separated into two clusters (Fig. 2C). The first cluster was composed of fourteen samples, three of which were from Ningxia province and eleven from Gansu Province. The second cluster comprised two E. intermedia samples in Gansu Province. Eleven E. intermedia samples in Gansu province and three in Ningxia province clustered in one class, which might be due to the adjacency of the two provinces and the proximity of these fourteen sampling sites. The other two areas of Gansu province were in the second cluster mainly because the sampling points were in the Northwest direction and were far from the first fourteen sampling points.

It is difficult to identify the three Ephedra species and their geographical origins with the uniform criterion. The samples with low similarities are easily identified at high Euclidean distances. The samples with high similarities are not easily identified, and their discriminations are often at a low Euclidean distance. E. sinica, E. intermedia, and E. przewalskii are different species with low similarity, and are distinguished at Euclidean distance 15. E. sinica from different provinces are not easily identified because of their high intraspecific similarity, and they are distinguished at Euclidean distance 3.5 generally. E. intermedia are all from Gansu Province except adjacent Ningxia, and have high similarities. Two samples of them are identified at Euclidean distance 15, and the other samples are difficult to identify.

A slight overlap occurred between E. sinica and E. intermedia and the geographical origins of the samples probably because the geographical location was close and the ecological environment was similar ${ }^{24}$. Subsequently, a radar plot was used to further study the discrimination of the samples from different regions and various species.

Distinguishing species and geographical origins of samples by radar plot. To visually compare the results, we constructed a radar plot to classify the Ephedra samples. This method allows routine, simple, and rapid discrimination ${ }^{25}$. It was used for distinguishing the geographical origins and species of the Ephedra samples based on six elements, namely, N, K, Mg, P, Fe, and B. These elements were chosen because their relative standard deviation (RSD) were high in Ephedra samples. Figure 3A-C showed the distributions of the elemental patterns of three Ephedra species based on the mean content of the six elements. E. sinica, E. intermedia and E. przewalskii presented clearly different characteristic patterns and were easily distinguished. This finding corresponded with the HCA results. Radar plot analyses were performed for 17 E. sinica, 16 E. intermedia and 5 E. przewalskii samples collected from different regions of 6 provinces. Figure 3D-F show the differences in geographical origins of E. sinica, E. intermedia, and E. przewalskii samples, respectively. Some elements in one Ephedra species vary in different regions ${ }^{26}$. The $\mathrm{B}$ and $\mathrm{Mg}$ contents changed for E. sinica and E. intermedia samples from different sampling locations, whereas $\mathrm{N}$ and $\mathrm{K}$ contents revealed different patterns for E. przewalskii samples from five 


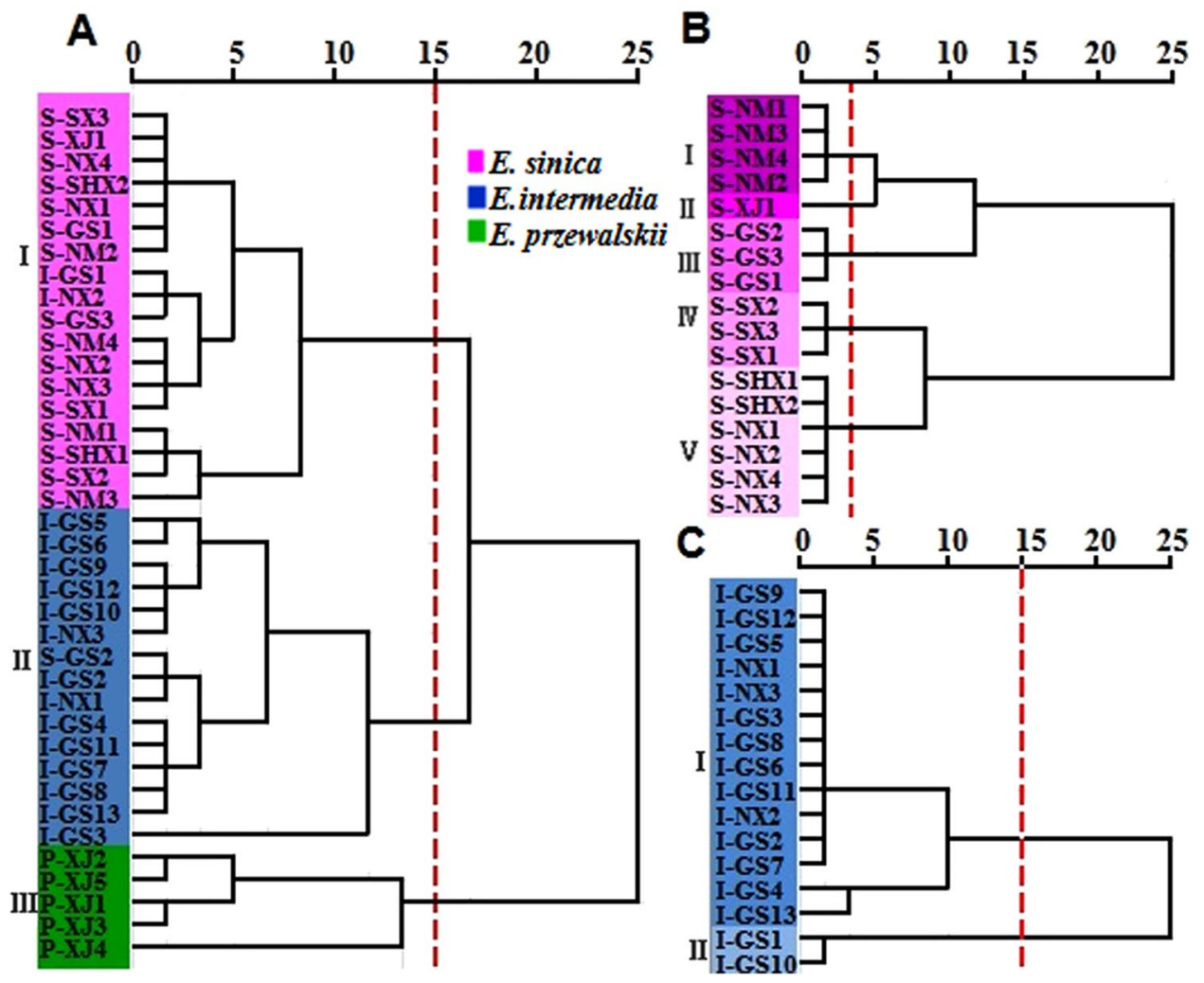

Figure 2. Dendrograms of hierarchical cluster analysis (HCA) based on 15 elements for Ephedra samples. (A) Showed 38 samples of three Ephedra species; (B) showed E. sinica samples from 17 different origins; (C) showed E. intermedia samples from 16 different origins. S-NM: E. sinica samples from Inner Mongolia; S-NX: E. sinica samples from Ningxia; S-GS: E. sinica samples from GanSu; S-SX: E. sinica samples from ShanXi; S-SHX: $E$. sinica samples from ShaanXi; S-XJ: E. sinica samples from Sinkiang; I-NX: E. intermedia samples from Ningxia; I-GS: E. intermedia samples from GanSu; P-XJ: E. przewalskii samples from Sinkiang.

different areas. Therefore, this method illustrated the geographical origins of different samples from the same species. Figure 3D-F also illustrated that the same species in different samples exhibited similar elemental pattern characteristics, indicating that the samples from the same species were of similar genetic background. However, the visual chart from the radar plot analysis lacked the specific indexes to describe the exact differences, which decreased the confidence level of the results. Therefore, principal component analysis (PCA) was subsequently performed.

Identification of species and geographical origins of samples by PCA. PCA was performed by factor analysis in SPSS software. PCA was implemented on element contents based on the 15 variables to classify the 38 Ephedra samples from different species and geographical origins. Table 1 showed the vectors and cumulative contribution of variance of the first four PCs (PC1-4). A four-factor model (the first four PCs with eigenvalues $>1$ ) can explain $81.294 \%$ of the total variability in the original data ${ }^{21}$. The PC1, PC2, PC3, and PC4 contributed $53.452 \%, 12.633 \%, 8.423 \%$, and $6.786 \%$ of the total variance, respectively. The first four PCs demonstrated that the $\mathrm{N}, \mathrm{K}, \mathrm{Cl}, \mathrm{Na}, \mathrm{B}, \mathrm{Mn}$, and Cu weights were high in $\mathrm{PC} 1$; P content loaded highly in PC2; and Mg played a major feature content in PC3 and PC4. The 81.294\% contribution varied from PC1 to PC4. Therefore, the elements $\mathrm{N}, \mathrm{K}, \mathrm{B}, \mathrm{Mn}, \mathrm{Na}, \mathrm{Cu}, \mathrm{Cl}, \mathrm{P}$, and $\mathrm{Mg}$ were regarded as the characteristic elements in the Ephedra samples. These elements may be treated as the most powerful referents of Ephedra samples.

Figure $4 \mathrm{~A}$ showed the score plot of the first two PCs which accounted for $66.08 \%$ of total variance in raw data $(\mathrm{PC} 1=53.45 \%, \mathrm{PC} 2=12.63 \%)$. A basic separation between $E$. sinica and $E$. intermedia could be observed, with $E$. przewalskii at the middle ${ }^{27}$. The corresponding loading plot (Fig. 4B) described the variables related to the separation, and the elements $\mathrm{N}, \mathrm{K}, \mathrm{B}, \mathrm{Mn}, \mathrm{Na}, \mathrm{Cu}, \mathrm{Cl}$, and $\mathrm{P}$ controlled the discrimination of the three Ephedra species.

The PCA score plots (Supplementary Fig. S1A) illustrated a separation pattern of the E. sinica samples, and the corresponding loading plot (Supplementary Fig. S1B) showed that $\mathrm{K}, \mathrm{Cu}, \mathrm{Sr}, \mathrm{Na}$, and $\mathrm{Cl}$ influenced the separation of E. sinica from different regions. The samples from six growing areas could be approximately separated. Table 2 indicates that the first three PCs (PC1-3), which have eigenvalues $>1$, explained $79.595 \%$ of the total variability among the 15 variables in the original data of E. sinica samples, where PC1, PC2, and PC3 contributed $60.15 \%, 12.46 \%$, and $6.99 \%$ of the total variance ${ }^{28}$. Supplementary Fig. S1C displays the separation pattern of the E. intermedia samples, whereas Supplementary Fig. S1D presents the corresponding loading plot, illustrating the variables related to the separation. $\mathrm{N}, \mathrm{Mn}, \mathrm{Cu}, \mathrm{Mo}$, and $\mathrm{Zn}$ affected the discrimination of E. intermedia samples. 
A E. sinica

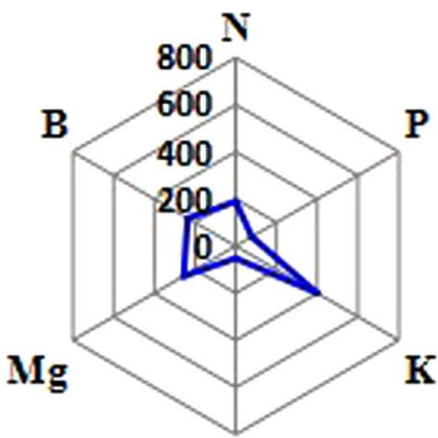

$\mathrm{Fe}$

D

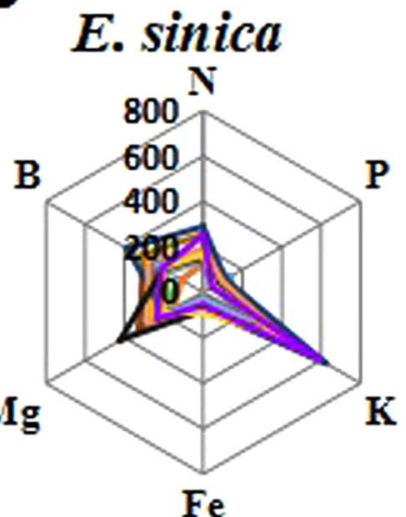

B E. intermedia

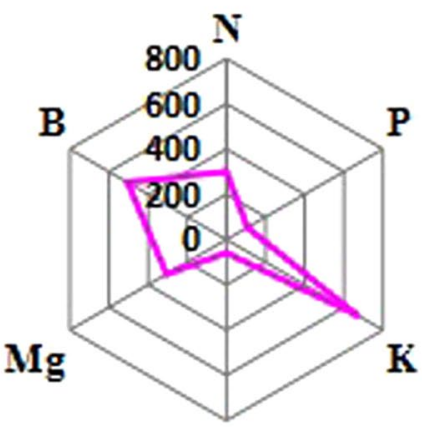

$\mathrm{Fe}$

E

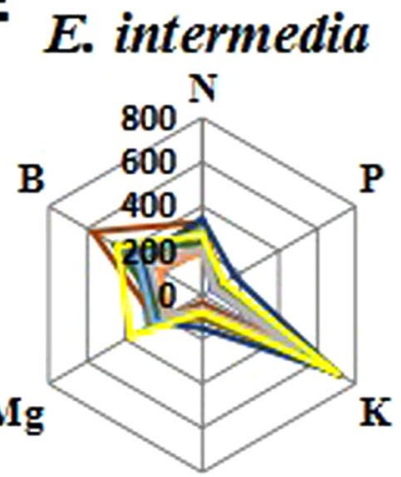

$\mathrm{Fe}$

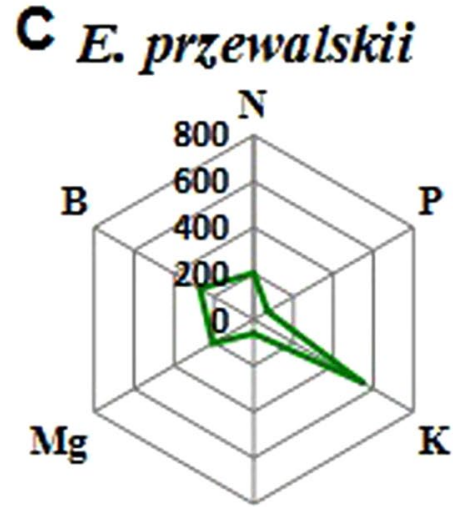

$\mathrm{Fe}$

F

E. przewalskii

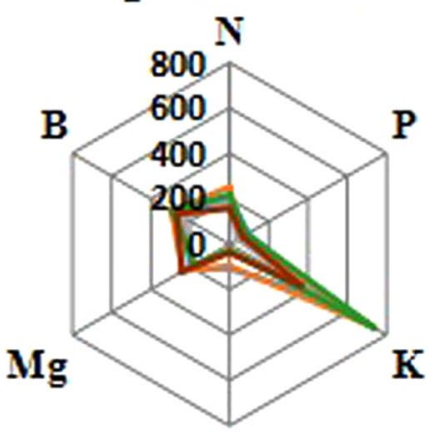

$\mathrm{Fe}$

Figure 3. A radar plot showing the difference in species and geographical origins of Ephedra samples based on six elements (B, N, P, K, Mg, and Fe). (A) Showed the elements average contents of E. sinica; (B) showed the elements average contents of E. intermedia; (C) showed the elements average contents of E. przewalskii; (D) showed the elements contents of E. sinica from 17 different origins; (E) showed the elements contents of $E$. intermedia from 16 different origins; (F) showed the elements contents of E. przewalskii from 5 different origins.

\begin{tabular}{|c|c|c|c|c|}
\hline \multirow[b]{2}{*}{ Items } & \multicolumn{4}{|c|}{ Principal component } \\
\hline & 1 & 2 & 3 & 4 \\
\hline $\mathrm{N}$ & 0.851 & 0.357 & -0.143 & -0.088 \\
\hline $\mathrm{K}$ & 0.816 & 0.307 & -0.207 & -0.058 \\
\hline S & 0.342 & -0.716 & -0.005 & -0.002 \\
\hline $\mathrm{Ca}$ & 0.733 & -0.422 & -0.097 & 0.154 \\
\hline $\mathrm{Mg}$ & 0.040 & -0.197 & 0.569 & 0.745 \\
\hline $\mathrm{P}$ & -0.038 & 0.851 & 0.202 & 0.165 \\
\hline $\mathrm{Fe}$ & 0.661 & 0.187 & -0.464 & 0.421 \\
\hline $\mathrm{Cl}$ & 0.835 & -0.241 & -0.194 & -0.047 \\
\hline $\mathrm{Sr}$ & 0.799 & 0.081 & -0.305 & 0.357 \\
\hline $\mathrm{Na}$ & 0.888 & -0.188 & 0.072 & -0.116 \\
\hline B & 0.829 & 0.050 & 0.313 & -0.127 \\
\hline $\mathrm{Mn}$ & 0.880 & -0.052 & -0.061 & -0.012 \\
\hline $\mathrm{Zn}$ & 0.762 & -0.105 & 0.368 & -0.203 \\
\hline $\mathrm{Cu}$ & 0.883 & 0.211 & 0.190 & -0.143 \\
\hline Mo & 0.766 & 0.153 & 0.449 & -0.050 \\
\hline Variance (\%) & 53.452 & 12.633 & 8.423 & 6.786 \\
\hline Cumulative variance (\%) & 53.452 & 66.085 & 74.508 & 81.294 \\
\hline
\end{tabular}

Table 1. The vectors and cumulative contribution of variance of the first four principal components. 
A

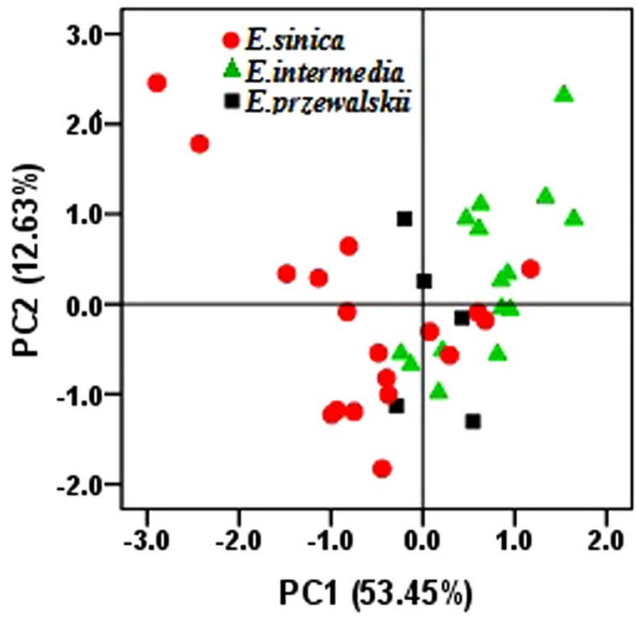

B

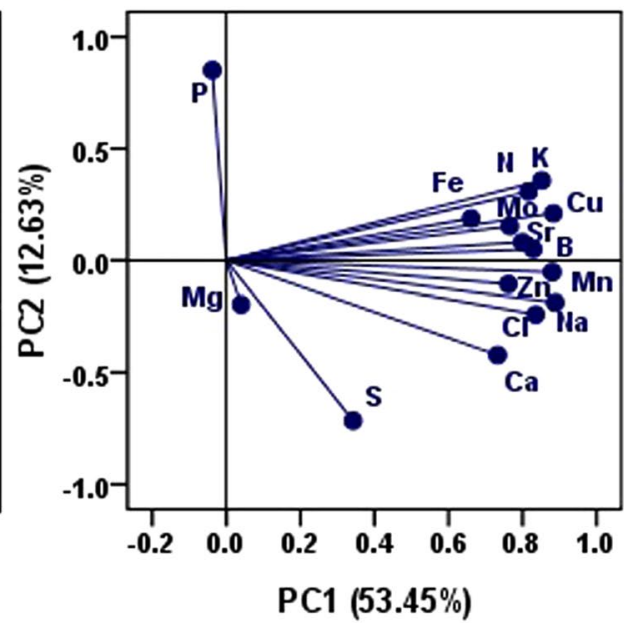

Figure 4. Principal component analysis (PCA) based on 15 elements in Ephedra samples. Panel (A,B) illustrate the score plot and the corresponding loading plot of 38 Ephedra samples from different species. Grouping according to species was shown by principle components 1 and 2, which explained $53.45 \%$ and $12.63 \%$ of the variance, respectively.

\begin{tabular}{|l|l|l|l|l|l|l|l|}
\hline \multirow{2}{*}{ Component } & \multicolumn{3}{|l|}{ E. sinica } & \multicolumn{3}{l|}{ E. intermedia } \\
\cline { 2 - 3 } \cline { 7 - 8 } & Total & \% of Variance & Cumulative \% & Component & Total & \% of Variance & Cumulative \% \\
\hline 1 & 9.023 & 60.153 & 60.153 & 1 & 6.206 & 41.375 & 41.375 \\
\hline 2 & 1.868 & 12.455 & 72.608 & 2 & 2.228 & 14.855 & 56.229 \\
\hline 3 & 1.048 & 6.988 & 79.595 & 3 & 1.607 & 10.712 & 66.942 \\
\hline & & & & 4 & 1.519 & 10.126 & 77.068 \\
\hline & & & & 5 & 1.106 & 7.374 & 84.442 \\
\hline
\end{tabular}

Table 2. Cumulative contribution of variance of the principal components.

The plot of E. intermedia samples was defined by the PC1 and PC2, which explained $41.38 \%$ and $14.86 \%$ of the variance, respectively. The E. intermedia samples from Ningxia and Ganshu were distinguished.

Clearly, the PCA results obtained were preliminary, and no obvious separation between Ephedra samples of different species and regions were observed in the PCA score plot according to element contents. Some overlaps were observed in the three Ephedra samples. Therefore, discriminant analysis (DA) was used to improve the separation and to further identify the authenticity of the samples.

Discrimination of species and geographical origins of samples based on DA. DA was applied to classify groups of Ephedra samples from different species and geographical origins based on element contents. The calculation was carried out using nine variables ${ }^{25}$, namely, $\mathrm{Ca}, \mathrm{S}, \mathrm{P}, \mathrm{Zn}, \mathrm{Mg}, \mathrm{Fe}, \mathrm{Mn}, \mathrm{Na}$, and $\mathrm{B}$ contents, to classify the three Ephedra species, and the other elements cannot be used for the discriminant function due to their insignificant discrimination effects.

Figure 5A shows the distribution patterns of the three Ephedra species in the plot defined by the discriminant functions. The variations between groups were explicated by the discriminant functions 1 (57.0\%) and 2 (43.0\%). Samples of E. przewalskii were completely differentiated from that of E. sinica and E. intermedia. Figure 5B represents the load correlation of the selected elements from all samples in the plane designed by the first two discriminant functions (F1 and F2). F1 contributed $57.0 \%$ of the variance, affording the primary species identification in all of the samples, and was positively correlated with the contents of $\mathrm{Ca}, \mathrm{Mg}, \mathrm{Zn}$ and B. F2 provided $43.0 \%$ of the variance and positively correlated with $\mathrm{Na}, \mathrm{Ca}$, and $\mathrm{Fe}$ contents ${ }^{29} . \mathrm{Zn}, \mathrm{B}, \mathrm{Ca}$, and $\mathrm{Na}$ were regarded as the most useful variables for species identification in all of the samples according to the correlation between Fig. 4A,B. This study showed that the samples from different species were plotted in different spaces.

DA was further implemented based on the contents of eleven elements, namely, P, Mg, Sr, Fe, Mo, K, N, Na, $\mathrm{S}, \mathrm{Ca}$, and $\mathrm{Cl}$ of $E$. sinica samples from different regions, as shown in Fig. 5C. The distribution pattern of E. sinica samples was defined by the discriminant functions 1 and 2 , and the two functions explained $97.8 \%$ and $1.2 \%$ of the variance, respectively. The E. sinica samples from different regions were completely separated. By using DA of $E$. sinica samples, we were able to distinguish the different samples from Inner Mongolia, Ningxia, Gansu, Shanxi, Shaanxi, and Sinkiang of China and observed the projections, which were located in different dimensions of the chart. F1 represented $97.8 \%$ of the variance, provided the main separation between the six provinces, and 
A
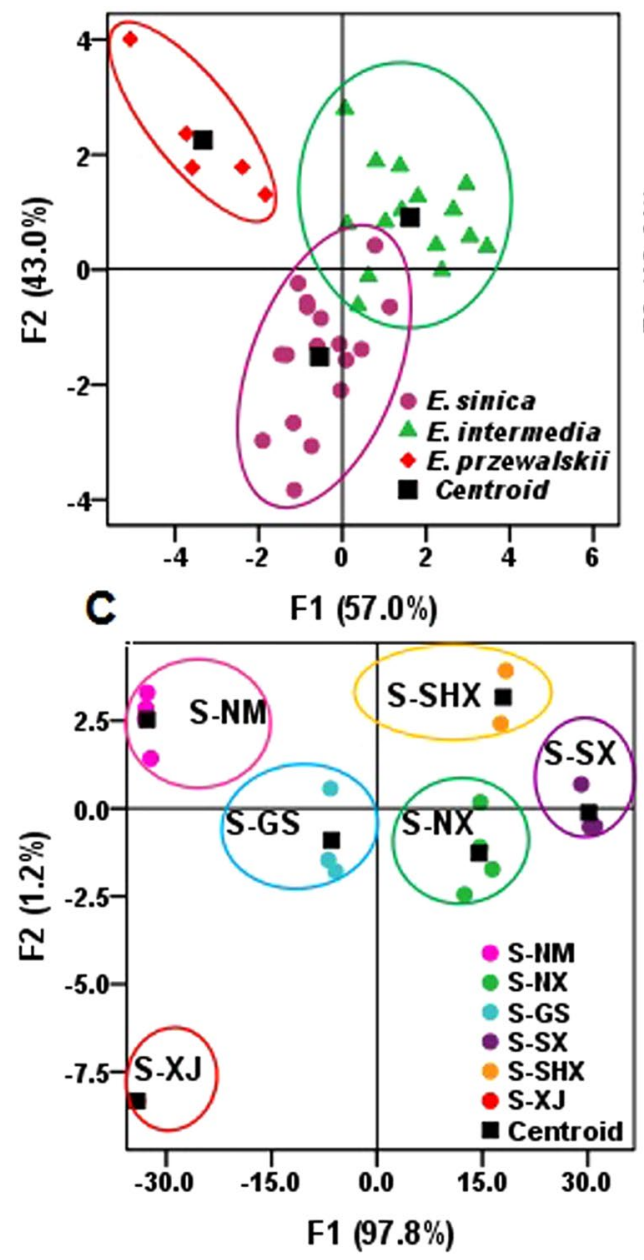

B
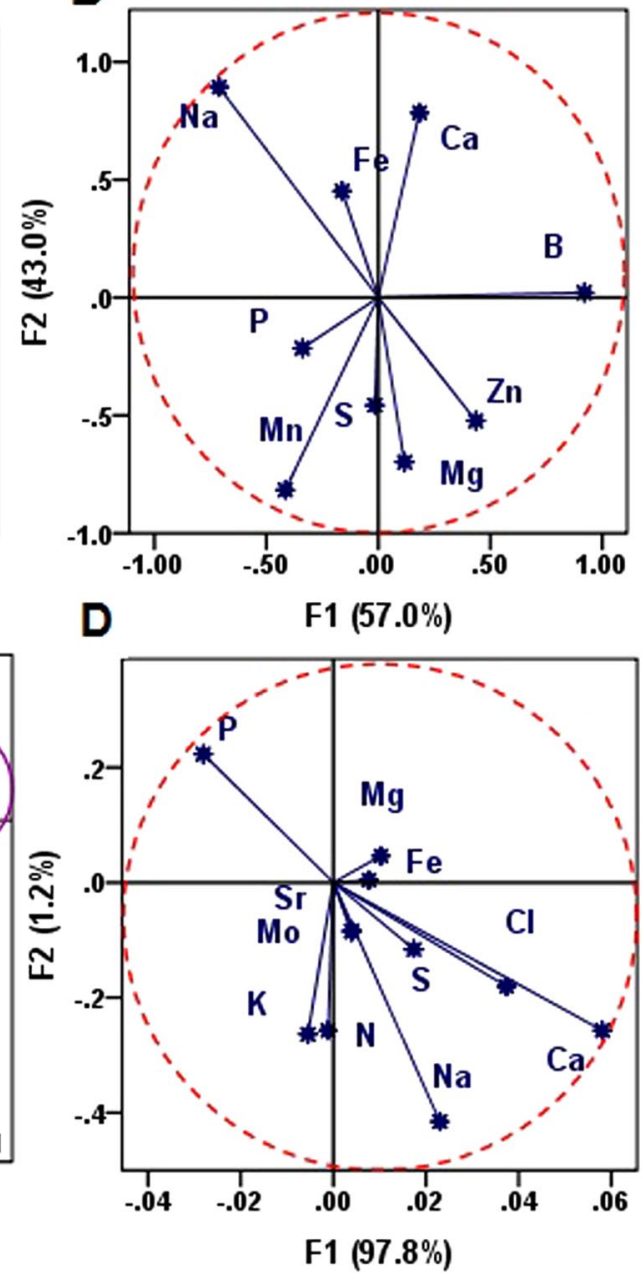

Figure 5. Discrimination analysis for Ephedra samples from different species and regions (A) The discrimination of three species of Ephedra samples (E. intermedia, E. sinica, E. przewalskii); (B) Correlation chart between the selected variables and the discriminant functions for the 38 Ephedra samples; (C) The discrimination of $E$. sinica samples from different geographical regions; (D) Correlation chart between the selected variables and the discriminant functions for E. sinica samples.

exhibited a strongly positive correlation with $\mathrm{Na}, \mathrm{Ca}, \mathrm{Cl}$, and $\mathrm{S}$ contents. $\mathrm{F} 2$ accounted for $1.2 \%$ of the variance and was positively correlated with $\mathrm{Mg}$ and $\mathrm{P}$ contents (Fig. 5D). Therefore, the main separators between the six provinces were $\mathrm{Na}, \mathrm{Ca}, \mathrm{Cl}, \mathrm{S}, \mathrm{Mg}$, and $\mathrm{P}$.

DA was performed based on the contents of fourteen elements, namely, $\mathrm{N}, \mathrm{P}, \mathrm{K}, \mathrm{S}, \mathrm{Ca}, \mathrm{Mg}, \mathrm{Fe}, \mathrm{Mn}, \mathrm{Na}, \mathrm{Cl}, \mathrm{Sr}$, $\mathrm{Cu}, \mathrm{Zn}$, and $\mathrm{B}$, of E. intermedia samples from different regions. These elements were chosen as the variables of the discriminant function because of their significant influences. The distribution pattern of $E$. intermedia samples was defined by the discriminant function 1 , which explained $100.0 \%$ of the variance. The E. intermedia samples from different regions were completely separated.

To check the reliability of the DA classification model, we performed a cross-validation procedure to calculate the classification and probability of the Ephedra samples ${ }^{24}$. Table 3 displays the cross-validation results together with the classification of Ephedra samples by the DA model. The results showed that $92.1 \%$ of all Ephedra samples were correctly classified, among which $100 \%$ of $E$. przewalskii were correctly differentiated from the $E$. sinica and E. intermedia samples, and $100 \%$ of 17 E. sinica and 16 E. intermedia samples from different growing provinces were correctly authenticated ${ }^{23}$. These results were parallel with those of previous studies. Therefore, multi-element analysis with chemometrics method is a promising fingerprinting analytical strategy for classifying Ephedra samples.

\section{Materials and Methods}

Materials. In this study, the herbaceous stems of E. sinica, E. intermedia and E. przewalskii were collected from 38 producing areas in six provinces of China, namely, Inner Mongolia, Ningxia, Gansu, Shanxi, Shaanxi, and Sinkiang, in September and October 2012 (Supplementary Table S2 and Fig. S2). In each producing area, 5 sampling sites were selected to collect $500 \mathrm{~g}$ plant samlpes ( $100 \mathrm{~g}$ for one sampling site), the distance between two sampling locations were above 200 meters to ensure the samples to be representative. 


\begin{tabular}{|c|c|c|c|c|c|c|c|c|}
\hline \multirow[b]{2}{*}{ Origin } & \multicolumn{8}{|c|}{ Assigned species for Ephedra samples with 9 variables } \\
\hline & \multicolumn{2}{|l|}{ E. sinica } & \multicolumn{2}{|c|}{ E. intermedia } & \multicolumn{2}{|c|}{ E. przewalskii } & Total & Correct (\%) \\
\hline E. sinica & \multicolumn{2}{|l|}{15} & \multicolumn{2}{|l|}{2} & \multicolumn{2}{|l|}{0} & 17 & 88.2 \\
\hline E. intermedia & \multicolumn{2}{|l|}{1} & \multicolumn{2}{|l|}{15} & \multicolumn{2}{|l|}{0} & 16 & 93.8 \\
\hline E. przewalskii & \multicolumn{2}{|l|}{0} & \multicolumn{2}{|l|}{0} & \multicolumn{2}{|l|}{5} & 5 & 100.0 \\
\hline Total & \multicolumn{2}{|l|}{16} & \multicolumn{2}{|l|}{17} & \multicolumn{2}{|l|}{5} & 38 & 92.1 \\
\hline \multirow{2}{*}{ Origin } & \multicolumn{8}{|c|}{ Assigned origin for $E$. sinica samples with 11 variables } \\
\hline & S-NM & S-NX & S-GS & S-SX & S-SHX & S-XJ & Total & Correct (\%) \\
\hline S-NM & 4 & 0 & 0 & 0 & 0 & 0 & 4 & 100.0 \\
\hline S-NX & 0 & 4 & 0 & 0 & 0 & 0 & 4 & 100.0 \\
\hline S-GS & 0 & 0 & 3 & 0 & 0 & 0 & 3 & 100.0 \\
\hline S-SX & 0 & 0 & 0 & 3 & 0 & 0 & 3 & 100.0 \\
\hline S-SHX & 0 & 0 & 0 & 0 & 2 & 0 & 2 & 100.0 \\
\hline S-XJ & 0 & 0 & 0 & 0 & 0 & 1 & 1 & \begin{tabular}{|l|}
100.0 \\
\end{tabular} \\
\hline Total & 4 & 4 & 3 & 3 & 2 & 1 & 17 & 100.0 \\
\hline \multirow{2}{*}{ Origin } & \multicolumn{8}{|c|}{ Assigned species for $E$. intermedia samples with 14 variables } \\
\hline & \multicolumn{3}{|l|}{ S-NX } & \multicolumn{3}{|l|}{ S-GS } & Total & Correct $(\%)$ \\
\hline S-NX & \multicolumn{3}{|l|}{3} & \multicolumn{3}{|l|}{0} & 3 & 100 \\
\hline S-GS & \multicolumn{3}{|l|}{0} & \multicolumn{3}{|l|}{13} & 13 & 100 \\
\hline Total & \multicolumn{3}{|l|}{3} & \multicolumn{3}{|l|}{13} & 16 & 100 \\
\hline
\end{tabular}

Table 3. Classification Results of Ephedra samples using discriminant analysis.

Sample preparation. The herbaceous stems of the samples were rinsed with the deionized water and dried at $105^{\circ} \mathrm{C}$. The dried samples were ground into fine powders of 100 mesh and stored in plastic bags at room temperature before analysis. The microwave assisted digestion was processed for the Ephedra samples (in triplicate) by a Mars-6 Microwave System (CEM Co., Ltd, U.S.), and the following project was used: About $1.000 \mathrm{~g}$ sample was precisely weighed inside teflon digestion vessels, and digested in the liquid of $3.0 \mathrm{~mL} \mathrm{H}_{2} \mathrm{O}_{2}$ and $5.0 \mathrm{~mL} \mathrm{HNO}_{3}$ with a three-step procedures (first: $120^{\circ} \mathrm{C} / 20 \mathrm{~min}$; second: $160^{\circ} \mathrm{C} / 20 \mathrm{~min}$; third: $180^{\circ} \mathrm{C} / 45 \mathrm{~min}$ ). Then the digested solution was evaporated to dryness on a hot plate with $150^{\circ} \mathrm{C}$. The digestions were cooled to room temperature, and diluted with deionized water to $10 \mathrm{~mL}$ in a volumetric flask.

ICP-MS measurements. $\quad \mathrm{N}, \mathrm{P}, \mathrm{K}, \mathrm{S}, \mathrm{Ca}, \mathrm{Mg}, \mathrm{Fe}, \mathrm{Mn}, \mathrm{Na}, \mathrm{Cl}, \mathrm{Sr}, \mathrm{Cu}, \mathrm{Zn}, \mathrm{B}$, and Mo were determined using ICP-MS (NexION 300D, PerkinElmer Instrument Co., U.S.) following the modified JIS K0133-2007 method(Japanese Industrial Standards Committee 2007) in Beijing ZKLH Analyzing \& Testing Center. The parameters of the instrument were optimized as follows: sample uptake of $1.0 \mathrm{~mL} / \mathrm{min}$, radio frequency power of $1600 \mathrm{~W}$, carrier gas flow rate of $1 \mathrm{~L} / \mathrm{min}$, plasma gas flow rate of $18.0 \mathrm{~L} / \mathrm{min}$, auxiliary flow rate of $1.20 \mathrm{~L} / \mathrm{min}$, dwell time of $50.0 \mathrm{~ms}$, scan time of $20 \mathrm{~s}$, and integral time of $1 \mathrm{~s}$.

Statistical analysis. Excel 2010 and SPSS 21.0 software were used for data analysis. The Ephedra samples were discriminated by radar plot analysis, element fingerprint analysis, and multi-element analysis, including principal component analysis (PCA), hierarchical cluster analysis (HCA) ${ }^{21}$, and discriminant analysis (DA). Elemental fingerprint, HCA, PCA and DA were based on all of the 15 elements from objects of study, respectively. The radar plot analysis was based on the six elements of $\mathrm{N}, \mathrm{K}, \mathrm{Mg}, \mathrm{P}, \mathrm{Fe}$, and $\mathrm{B}$ with high relative standard deviation. PCA was used to primarily evaluate between-class similarity and achieve dimension reduction. HCA was a classification procedure which involved the measurement of similarity between the objects to be clustered. The amalgamation rule was based on Ward's method, and the squared Euclidean distance was performed for the similarity measurement. Samples were grouped in clusters based on their distance and similarities ${ }^{30}$. DA classified the maximum variance between groups and minimum variance within groups by creating new variables, maximizing the variance between categories and minimizing the variance within categories. This technique is an effective and well-known method for classification ${ }^{23}$.

\section{Conclusion}

In this paper, we measured the contents of 15 plant essential elements in E. sinica, E. intermedia and E. przewalskii, built their element fingerprints, investigated the mineral element ability to differentiate the three species and their geographical origins with chemometrics method. The radar plot and HCA clearly ditinguished the three Ephedra species, DA completely differentiated E. przewalskii from E. sinica and E. intermedia, correctly classified the geographical origins of E. sinica and E. intermedia samples. The combination of the element fingerprints and multivariate statistical techniques could be a practical tool for identifying the geographical origins and species of Mahuang.

Data Availability. All data generated or analysed during this study are included in this published article (and its Supplementary Information files). 


\section{References}

1. Pharmacopoeia Committee of People's Republic of China. Pharmacopoeia of the P. R. China. Vol 1. Beijing: China Medical Science Press 1, 320-321(2015).

2. Abourashed, E. A., El-Alfy, A. T., Khan, I. A. \& Walker, L. Ephedra in perspective-a current review. Phytotherapy Research Ptr 17, 703-12 (2003)

3. Andraws, R. P. \& Brown, D. L. Cardiovascular Effects of Ephedra Alkaloids: A Comprehensive Review. Progress in Cardiovascular Diseases 47, 217-225 (2005).

4. Ma, G. et al. Pharmacological effects of ephedrine alkaloids on human alpha(1)- and alpha(2)-adrenergic receptor subtypes. Journal of Pharmacology \& Experimental Therapeutics 322, 214 (2007).

5. Amakura, Y. et al. Characterization of phenolic constituents from ephedra herb extract. Molecules 18, 5326 (2013).

6. Zhao, W. et al. Chemical constituents of the stems of Ephedra sinica. Journal of Asian Natural Products Research 11, 168 (2009).

7. Cottiglia, F. et al. Phenolic constituents from Ephedra nebrodensis. Natural Product Research 19, 117 (2005).

8. Zang, X. et al. A-type proanthocyanidins from the stems of Ephedra sinica (Ephedraceae) and their antimicrobial activities. Molecules 18, 5172-5189 (2013).

9. Wang, Q. et al. A pure polysaccharide from Ephedra sinica treating on arthritis and inhibiting cytokines expression. International Journal of Biological Macromolecules 86, 177 (2016).

10. Shen, G. M. Distribution and evolution of the genus Ephedra in China. Acta Botanica Yunnanica 17, 15-20 (1995).

11. Zhong, X. J. \& Tan, Y. F. Research progress of soil factor influences on the quality of genuine medicinal materials. Journal of Southern Agriculture 43, 1708-1711 (2012).

12. Hong, H. et al. Surveys on resources and varieties on Chinese markets of crude drug mahuang. China journal of Chinese materia medica 36, 1129 (2011).

13. Flora of China [Internet]. Ephedra przewalskii, Ephedra intermedia. 1999 [cited 2016 Jun 3]. Available from: http://foc.eflora.cn/ volume.aspx?num $=4$

14. Xu, K., Li, N. \& Wang, Y. Fast discrimination of traditional Chinese medicine according to geographical origins with FTIR spectroscopy and advanced pattern recognition techniques. Optics Express 14, 7630-5 (2006).

15. Barbosa, R. M. et al. The use of advanced chemometric techniques and trace element levels for controlling the authenticity of organic coffee. Food Research International 61, 246-251 (2014).

16. Zhao, Y. et al. Discrimination of geographical origin of cultivatedPolygala tenuifoliabased on multi-element fingerprinting by inductively coupled plasma mass spectrometry. Scientific Reports 7 (2017).

17. Zheng, K. \& Yan, C. Application of ICP-AES with microwave digestion to detect trace elements in oysters from Jiaozhou Bay, China. Journal of Ocean University of China 10, 301-304 (2011).

18. Marschner, P. Marschner's Mineral Nutrition of Higher Plants. 24 (2011).

19. Fei, T. et al. Determination of trace elements in Chinese medicinal plants by instrumental neutron activation analysis. Journal of Radioanalytical \& Nuclear Chemistry 284, 507-511 (2010).

20. Chen, Y. X., Yu, M. G., Xu, J., Chen, X. C. \& Shi, J. Y. Differentiation of eight tea (Camellia sinensis) cultivars in China by elemental fingerprint of their leaves. Journal of the Science of Food \& Agriculture 89, 2350-2355 (2009).

21. Yuan, X. F. et al. Establishment of element fingerprint and multielement analysis of Fritillaria thunbergii by inductively coupled plasma optical emission spectrometry. Biological Trace Element Research 135, 304-313 (2010).

22. Xia, W. U., Kang, Z., Zhao, F., Zheng, Y. \& Yantuan, L. I. Construction of Inorganic Elemental Fingerprint and Multivariate Statistical Analysis of Marine Traditional Chinese Medicine Meretricis concha from Rushan Bay. Journal of Ocean University of China 13, 712-716 (2014).

23. Liu, X. et al. The classification of sea cucumber (Apostichopus japonicus) according to region of origin using multi-element analysis and pattern recognition techniques. Food Control 23, 522-527 (2012).

24. Sun, S. M., Guo, B. L., Wei, Y. M. \& Fan, M. T. Multi-element analysis for determining the geographical origin of mutton from different regions of China. Food Chemistry 124, 1151-1156 (2011).

25. Cheajesadagul, P., Arnaudguilhem, C., Shiowatana, J., Siripinyanond, A. \& Szpunar, J. Discrimination of geographical origin of rice based on multi-element fingerprinting by high resolution inductively coupled plasma mass spectrometry. Food Chemistry 141, 3504-3509 (2013).

26. Zhao, H. \& Zhang, S. Effects of sediment, seawater, and season on multi-element fingerprints of Manila clam (Ruditapes philippinarum) for authenticity identification. Food Control 66, 62-68 (2016).

27. Owen, J. D., Kirton, S. B., Evans, S. J. \& Stair, J. L. Elemental fingerprinting of Hypericum perforatum (St John's Wort) herb and preparations using ICP-OES and chemometrics. J Pharm Biomed Anal 125, 15-21 (2016).

28. Shao, M. et al. Inorganic elemental determinations of marine traditional Chinese Medicine Meretricis concha from Jiaozhou Bay: The construction of inorganic elemental fingerprint based on chemometric analysis. Journal of Ocean University of China 15, 357-362 (2016).

29. Dinca, O. R. et al. Regional and Vintage Discrimination of Romanian Wines Based on Elemental and Isotopic Fingerprinting. Food Analytical Methods 9, 2406-2417 (2016).

30. Borges, E. M., Volmer, D. A., Brandelero, E., Gallimberti, M. \& Barbosa, F. Jr. Monitoring the Authenticity of Organic Grape Juice via Chemometric Analysis of Elemental Data. Food Analytical Methods 77, 1-8 (2015).

\section{Acknowledgements}

This work was supported by the National Natural Science Foundation of China (81760687).

\section{Author Contributions}

Y.Z. and F.M. conceived of and proposed the idea. Y.Z. designed the study. L.F. carried out the experiments, X. M. analyzed the data and wrote the manuscript. All Ephedra samples were collected by H.T., R.X. and Y.P. in the experiments. Professor Y.Y. and H.S. contributed to editing and proof-reading the manuscript. All the authors discussed the results and commented on the manuscript.

\section{Additional Information}

Supplementary information accompanies this paper at https://doi.org/10.1038/s41598-018-28558-9.

Competing Interests: The authors declare no competing interests.

Publisher's note: Springer Nature remains neutral with regard to jurisdictional claims in published maps and institutional affiliations. 
(i) Open Access This article is licensed under a Creative Commons Attribution 4.0 International License, which permits use, sharing, adaptation, distribution and reproduction in any medium or format, as long as you give appropriate credit to the original author(s) and the source, provide a link to the Creative Commons license, and indicate if changes were made. The images or other third party material in this article are included in the article's Creative Commons license, unless indicated otherwise in a credit line to the material. If material is not included in the article's Creative Commons license and your intended use is not permitted by statutory regulation or exceeds the permitted use, you will need to obtain permission directly from the copyright holder. To view a copy of this license, visit http://creativecommons.org/licenses/by/4.0/.

(C) The Author(s) 2018 